\section{Skeletal Biology: Definition}

Douglas H. Ubelaker

National Museum of Natural History,

Smithsonian Institution, Washington, DC, USA

\section{Brief Definition of the Topic}

Human skeletal biology emphasizes the dynamic nature and complexity of the human skeleton. Research in human skeletal biology frequently focuses on human remains recovered from archaeological contexts. Topics of research generally relate to health, the relationships among ancestral populations as revealed in biological distance studies, and functional morphology through related evaluations of behavior and use of the skeleton. Interpretations within the field recognize the mechanisms of growth and development, bone remodeling, sexual dimorphism, adult age changes, and population variation. More specifically, research foci can include skeletal evidence for disease, chemical analyses relating to diet, the growth and maintenance of bones and teeth, demographic reconstruction, trauma, cultural effects, biomechanical adaptation, and postmortem alterations. The term human skeletal biology is frequently used synonymously with the terms human osteology and bioarchaeology.

\section{Cross-References}

- Ancestry Assessment

Bioarchaeology: Definition

- Biological Distance in Bioarchaeology and Human Osteology

$\checkmark$ Bone, Trauma in

- Bone: Chemical Analysis

Dental Anthropology

\section{Further Reading}

Larsen, C.S., and P.S. Bridges. 1997. Skeletal biology. In History of physical anthropology: an encyclopedia, ed. F. Spencer, 937-943. New York: Garland Publishing.

Ubelaker, D.H. 2000. Methodological considerations in the forensic applications of human skeletal biology. In Biological anthropology of the human skeleton, ed. M.A. Katzenberg, and S.R. Saunders, 41-67. New York: Wiley-Liss. 